\title{
A FORÇA DAS COISAS: "ETAPAS DO DESENVOLVIMENTO HISTÓRICO” - NOTAS DE PESQUISA.
}

\author{
Reginaldo Carmello Corrêa de MORAES*
}

RESUMO: Este texto veio a constituir, modificado, o primeiro capítulo de nossa tese de mestrado - A Fênix tropical: nota crítica sobre o dualismo e a teoria da dependência, Faculdade de Filosofia, Letras e Ciências Humanas, Universidade de São Paulo. Trata dos seguintes temas: I - A "filosofia da história", o marxismo e a "objetividade"; II - O pensamento social brasileiro: as teorias do/sobre o desenvolvimento e o marxismo apologético: 1. ${ }^{\circ}$ Werner Baer: a "objetividade" conservadora contra as "paixðes" reformistas; 2. ' Carlos Lessa: Industrialização como “decisão"; 3. ' ISEB: objetividade reformista contra paixðes socialistas; $4{ }^{\circ}$ Maturidade politica contra a venturas socialistas; III - Os pressupostos comuns.

UNITERMOS: Filosofia da história; marxismo; objetivismo; desenvolvimentismo; reformismo; sociologia brasileira; nacionalismo; progressismo.

I - A "FILOSOFIA DA HISTÓRIA", O MARXISMO E A "OBJETIVIDADE'.

Nas ciências humanas, a reflexão sobre o desenvolvimento histórico tem como referência constante (e quase que obrigatória), seja pela sua influência nos "fatos", seja pelo seu caráter polêmico, o chamado marxismo clássico, ou seja, o marxismo do próprio Marx e de Engels. E $o$ aspecto que mais se tem destacado nessa corrente de pensamento é a ênfase sobre a "objetividade", tantas vezes interpretada, por marxistas e por não-marxistas, como a determinação necessária dos fenômenos pela consciência universal. Essa ênfase está ancorada nas heranças filosóficas proclamadas pelo próprio marxismo clássico. Este é um ponto complexo da teoria marxista, sendo impossível tematizar aqui os meandros da questão. Sumariamente, pode-se, ainda hoje, perguntar até que ponto o marxismo rompeu com a razão burguesa em todas as suas diferenciações. Neste sentido, cabe lembrar o esquema leninista, segundo o qual Marx seria herdeiro de três fontes: o socialismo francês, a economia política inglesa e a filosofia clássica alemã. Esta relação é estabelecida por Lenin de modo positivo. Ora, esse reconhecimento mesmo não seria indício de adesão a essa racionalidade? Não se poderia inverter o seu juízo, captando, nessa herança, um traço de adequação, ao invés de ruptura com o existente?

Por exemplo, no socialismo francês, Saint-Simon chega à idéia de uma sociedade que elimina a política propriamente dita e vive sob a administração científica e técnica, compreendidas num universo organizado. Do socialismo utópico tem-se a proposição autoritária de que o cientista é o organizador. Para Saint-Simon, a filo-

* Departamento de Ciências Sociais e Filosofia - Instituto de Letras, Ciências Sociais e Educação - UNESP 14.800 - Araraquara - SP. 
MORAES, R.C.C. de - A força das coisas: "etapas do desenvolvimento histórico" - notas de pesquisa. Trans/Form/Ação, São Paulo, 5: 43-53, 1982.

sofia do século XIX, "inventiva e organizadora", possibilitará a "regeneração do gênero humano, numa nova etapa do conhecimento, sob a direção dos cientistas e pensadores laicos"' (3, p. 257). Tal ideário concentra-se na frase-programa de $\mathrm{Re}$ nan: "organizar cientificamente a sociedade, tal é a última palavra da ciência moderna, tal é a sua audaciosa, mas legítima pretensão"' (12, p. 85).

A segunda fonte do marxismo, a economia política, tinha, como disse $\mathrm{He}$ gel, feito a astronomia do mundo burguês, isto é, tinha mostrado as leis objetivas da sociedade civil. Se o marxismo substituir o mundo da história, como relação social mediada pelas coisas, por uma natureza, um algo opaco, determinado, legislado, do qual se pode fazer a "astronomia" não terá também que substituir a praxis pela ação técnica, o proletariado pelo revolucionário profissional? (16, p. 89). A "necessidade objetiva do socialismo" - descoberta de uma ciência, o socialismo científico - se tornou suporte ideológico dos partidos socialistas do século XIX. Em que medida porém não depositou a consciência socialista, o saber e o segredo da história, num aparelho partidário que sobrevoa os acontecimentos?

A terceira fonte é o próprio Hegel, em cujo sistema a lógica da história, posta como necessária, contesta a consciência imediata, ao mesmo tempo que supõe a constituição de uma totalidade inteligível... mas para que consciência? Se, como lembra Merleau-Ponty (16, p. 6465) a filosofia marxista é o "segredo da existência" do proletariado, é um segredo que este último não possui. Este, para ser sujeito da verdade histórica, torna-se objeto, mercadoria. Sofre o processo de sua realização. O conceito, que é a forma real dessa história, pois revela a verdade sobre o processo, quem o define? Quem decifra o segredo da existência do proletariado?

O filósofo, para Hegel, se torna o "funcionário do universal":

"É na classe média, da qual fazem parte os funcionários do Estado, que encontramos a consciência do Estado e a cultura mais eminente. Deste modo, ela constitui o pilar principal sobre que repousa o edifício do Estado, no que se refere à honestidade e inteligência".

Esta apologia dos funcionários que operam de modo competente e sineira ao studio é complementar, em Hegel, ao desprezo pela opinião pública. Em apoio de seus argumentos, cita Ariosto: "O vulgo ignorante repreende todo mundo e mais fala do que menos entende $(19$, p. 318 , nota). Essa posição se radicaliza com a teoria do homem providencial que "exprime o fundamento e a essência de seu tempo e as realiza. Quem não é capaz de desprezar a opinião pública, tal como se faz ouvir aqui e ali, jamais realizará algo grande ( 9 , p. 304 e 318). Nestes termos, a razão científica e a razão de Estado são postas acima da sociedade.

Imerso nessa cultura, Engels dirá que o avanço do socialismo na Rússia e na Ásia requer a prioritária garantia dos "fundamentos materiais da sociedade ocidental", isto é, a expansão irrestrita do sistema conforme o modelo inglês, de modo que as contradições do capitalismo possam realizar-se. Essa fase seria a da revolução democrático-burguesa. E os atores que dominariam a cena, conduzidos pela mão firme e segura da necessidade histórica, seriam os liberais, não os socialistas *. Essa etapa, diria Plekhanov mais tarde, é que torna possível a chegada do movimento operário à maturidade política $(20$, p. 185). Pode-se ainda buscar justificativas para tais construções no próprio Marx de Revolução e Contra Revolução na Alemanha ** onde se encontram

* Trata-se de correspondência com Vera Zasulich e Kautsky, citada por Marian SA WER(20, p.141-142).

* Na verdade, estes artigos (15) são hoje atribuídos a Engels. 
MORAES, R.C.C. de - A força das coisas: "etapas do desenvolvimento histórico" - notas de pesqui-

sa. $\quad$ Trans/Form/Ação, São Paulo, 5: 43-53, 1982.

esses argumentos. Ou na célebre fórmula de $O$ Capital de que "os países adiantados colocam diante dos atrasados o espelho de sua história futura"' (14, p. XIV).

$\mathrm{Se}$ - para seguir a gnoseologia de Lenin (11) e Engels (6) - o socialismo científico (enquanto momento consciente) é reflexo daquilo que já é (a matéria), do processo histórico "real", ele tem igualmente o poder e o direito de arrancar um sentido da história oculto ao comum dos mortais. O objetivismo extremo pode desse modo legitimar o subjetivismo extremo - admitindo-se a Providência, justificase a Inquisição, dirá Merleau-Ponty (16, p.116-117).

II - O PENSAMENTO SOCIAL BRASILEIRO: AS TEORIAS DO/SOBRE O DESENVOLVIMENTISMO E O MARXISMO APOLOGÉTICO.

As reflexões acima nos vêm a propósito de autores que analisam a formação da sociedade brasileira, o papel do Estado e das classes sociais, o significado das "crises", etc.

Existe, nesse pensamento social brasileiro, uma tradição de "denúncia política": a invectiva contra os "erros e conspirações contra o interesse nacional"'. Sem mencionar os ecos do nativismo, a figura mais recente dessa apologia remonta, pelo menos, ao primeiro (e pioneiro) Caio Prado Junior, e reuniu, quase na mesma trincheira, ao longo de várias décadas, os mais diferentes e contraditórios personagens (desde isebianos a marxistas oficiais, tecnocratas independentes, cepalinos, trabalhistas e até integralistas). Neste ideário, a tese nacionalista vinha quase sempre acompanhada pela exigência obsessiva de "salvação da pátria".

A esse tom não parece escapar igualmente grande parte do jornalismo "de oposição" - mesmo após 1964 - que, assumindo a "autoconsciência da nação" busca ajuizar negativamente os erros dos planejadores oficiais da política econômica. Pode-se perguntar, neste último caso, de onde retiram, os aludidos críticos, sua proposta a alternativa ao capitalismo vigente, dito "selvagem". É conhecido o discurso que articula essas representações: postula um outro modelo socioeconômico, caracterizado pelo nacionalismo, defesa dos “interesses populares", redistribuição da renda, consolidação do mercado interno, reforço e legitimação dos canais da democracia representativa e parlamentar, etc. Mesmo assim, a questão é pertinente, tanto mais que a alternativa acenada apela, com freqüência, explicita ou implicitamente, para um enfoque normativo, corretor de anomias, enfoque segundo o qual as contradições se resolvem pela sua regulamentação, com que a nação, universal abstrato, se põe em paz consigo mesma, e realiza sua identidade até então em potência.

Por essa via, se procurará transformar o agora desta essência ainda não desenvolvida - a Nação - no "sujeito" que melhor encarne a fase de sua existência, dominando as virtualidades de seu desenvolvimento. Uma vez admitidos os fins acima (a "alternativa democrática capitalista") e mais os da luta contra a "deterioração dos termos de troca" e a favor da independência nacional, não é difícil precisar como e porque para essas correntes políticas e intelectuais é inoportuno teoricamente e injustificado praticamente que o proletariado "ice suas próprias bandeiras".

Nesta parte do artigo, tomo como objeto de investigação os textos de alguns estudiosos do período desenvolvimentista que focalizam e difundem aquela política no Brasil. Pretendo, através deles, indagar sobre os pressupostos e conseqüências de suas "teorias do Brasil". Os referidos escritos incluem-se em campos políticos diversos e mesmos opostos no plano empírico: Werner Baer, Carlos Lessa, os pensadores do ISEB, Leoncio Basbaum e Otávio Ianni. Em que pese essa diversidade, pretendo esclarecer que se estabelece 
MORAES, R.C.C. de - A força das coisas: "etapas do desenvolvimento histórico" - notas de pesquisa. Trans/Form/Ação, São Paulo, 5: 43-53, 1982.

uma proximidade essencial na forma e conteúdo de suas exposições.

Para adiantar sinteticamente o argumento, em ambos os lados, pode-se localizar a valorização de uma autoconsciência do país, a idéia de uma "razão nacional" de que alguns homens seriam os portadores, formulando e dando efetividade a medidas "científicas" de política econômica. $\mathrm{O}$ postulado do interesse nacional caminha de mãos dadas com a noção recorrente de que medidas conformes a esse critério podem e devem ser postas em prática para enfrentar a crise de lideranças de que sofreria o país. Para os autores mais críticos, esta última se concretizaria nos erros dos empresários nacionais e dos formuladores de política econômica, na inconsciência ou na falta de clareza sobre seus ef eitos *, na má-fé e oportunismo de sua inspiração, em seu teor conspiratório, moldado aos interesses de um capital estrangeiro classificado como predador $\mathrm{e}$ solidário do atraso. A reforma da nacionalidade coloca-se, então, como etapa da luta contra o obscurantismo e o atraso.

Esses arrancados podem ser vistos em dois níveis: no recorte formal dos próprios problemas eleitos pelos autores e na sua explicitação.

1. ${ }^{\circ}$ WERNER BAER: a "objetividade" conservadora contra as "paixões" reformistas.

Indagando sobre as fontes dos recursos para a industrialização brasileira no período $1947 / 60$, W. BAER destaca o papel "positivo" da inflação. O positivo assim é considerado em relação a um parâmetro não desvelado de imediato. Neste caso, a inflação tem um papel benéfico para a "economia", sendo esta identificada com a acumulação de capital $(1$, p. 95$)$. Por isso, a todo momento, qualquer força que dificulte a acumulação é negativa para a "economia", e, por isso, deve ser controlada.

Para este autor, o processo inflacionário força para baixo a renda real do "setor de consumo". Teríamos então uma poupança compulsória que reduziria as importações, além de aumentar a capacidade de produção para substituí-las. Isso aconteceria na medida em que aumentassem as margens de lucro dos fabricantes de produtos industriais substitutivos de importaç̃̃es. "A defasagem dos salários é pois uma condição indispensável para que o processo inflacionário possa ser produtivo" (16).

Por isso, o processo inflacionário teria eficácia para a Acumulação de Capital na medida em que sejam contidas as reivindicações salariais e na medida, ainda, em que os recursos não sejam desviados para investimentos improdutivos" $(1, p$. 101).

Até o momento em que Baer escrevia seu ensaio, os objetivos visados para "a economia" eram plenamente atingidos, isto é, conseguia-se manter e elevar a taxa de excedente extraído à força do trabalho**. O autor se apressa em argumentar que esse incremento não teve como contrapartida uma queda do nível de vida dos trabalhadores. Haveria, apenas, uma queda de sua participação no incremento do produto real, em favor do empresariado. Esta queda teria sido gerada pela densidade de capital das novas indústrias, isto é, pela defasagem entre os incrementos do número de trabalhadores e da produção (1, p.108). Em outros termos, teríamos aqui o "ajustamento na margem" a que se refere Lessa, como um dos fatores de absorção de tensões. Conforme este último autor, o dinamismo da economia bra-

- FURTADO chega a firmar, referindo-se à associação burguesia local-capital imperialista: "Do ponto de vista dos interesses da empresa, essa foi muitas vezes a atitude mais racional. Mas do ponto de vista nacional, a acumulação dessas decisð̃es individuais teria repercussð̃es que só a mais longo prazo seriam percebidas" - $(7$, p. 137).

** Cf. dados de BAER (1, p. 105), apontando para a queda da relação salário/valor adicionado na indústria, notadamente nos seus ramos mais dinâmicos. 
MORAES, R.C.C. de - A força das coisas: "etapas do desenvolvimento histórico" - notas de pesquisa. Trans/Form/Ação, São Paulo, 5: 43-53, 1982.

sileira permitia isso, "na medida em que possibilitava níveis crescentes de investimento, sem conduzir à perda absoluta de renda por outros setores da economia. A renda real do trabalhador urbano não decaíra e no cômputo final nenhum setor perdera posição em termos absolutos. Permitindo um ajustamento na margem, o crescimento econômico tornou compatível um processo de transferência forçada dos recursos adicionais gerados para o setor público e empresa (...) com a defesa dos níveis de consumo dos assalariados (via tentativas de contenção de preços dos produtos de subsistência), através de aplicação de medidas aparentemente incoerentes (13, p.45).

Existe ainda um outro fator que teria permitido absorver tensões nesse quadro de apropriação desigual do incremento de renda. A incapacidade dos assalariados em manter constante sua parte no produto nacional seria, por um lado, provocada pelo fato da recente industrialização, encontrando amplas reservas de mão-deobra rural, com grande contigente se urbanizando periodicamente $(1$, p. 108). Por outro lado, e não menos importante, está o fato político do quase absoluto controle governamental sobre os sindicatos.

Nesse sentido, Baer vê a crescente independência do movimento sindical no início dos anos 60 (1, p. 108-9), com um obstáculo possível ao desenvolvimento da "economia".

A esta representação da "economia", colocada enquanto universal abstrato, desvinculado das determinações de classe, correspondente a imagem duma razão que lhe é imanente. A questão é saber quem é o seu portador ou intérprete privilegiado. Quando Baer se refere (1, p. 269) à política econômica utilizando expressões como - "tais medidas eram consideradas..." - esse anonimato do sujeito (por quem "eram consideradas"?) não vem por acaso. Ele possibilita sua identificação indeterminada, vaga e por isto mesmo eficaz, com os tecnocratas do governo, supostamente "independentes" face aos interesses particulares. Tal coincidência existe quando Baer assinala a importância, em outro período (1968-73), dos técnicos governamentais no processo de crescimento econômico brasileiro e, portanto, no fortalecimento de um governo que os mantivesse como garantia de que "as políticas econômicas seriam levadas a cabo quaisquer que fossem os efeitos secundários sobre os vários grupos econômicos"' $(1$, p. 251).

Outras vezes, essa justificação do "autoritarismo esclarecido" será obrigada a admitir as contradições da dominação instrumental, do desacerto imediato que aparece entre a consciência tecnocrática e a economia de mercado. Assim, salta à sua frente, desafiadora, a pergunta sobre quais grupos e quais critérios o planejador deve levar em conta, visto que o projeto estatal pode entrar em oposição ao movimento do mercado, enquanto alocador de recursos. Um caso agudo dessa dificuldade é o problema dos parâmetros para avaliar a performance das empresas públicas: são eles definidos pelas metas privadas ou pelas sociais, ou ainda por ambas? $\mathrm{Na}$ verdade, responderá Baer, "um critério de lucratividade máxima e crescimento poderia facilmente contradizer metas sociais tais como maximização do emprego, suprir de insumos baratos as indústrias favorecidas pelas empresas governamentais produtoras de insumos, etc." (1, p. 281). Em suma, quem determina, legitimamente, as "necessidades" da preservação de todo social vigente?

\section{2. ${ }^{\circ}$ CARLOS LESSA: Industrializa-} ção como "decisão".

A atribuição de universalidade a interesses particularistas (e as dificuldades daí decorrentes) não é de estranhar nos escritos em que esse raciocínio é diretamente apreensível, nos princípios, demonstrações e conclusões assumidas. $\mathrm{O}$ fato, porém, é que isso ocorre, ambiguamente, em 
MORAES, R.C.C. de - A força das coisas: "etapas do desenvolvimento histórico" - notas de pesquisa. Trans/Form/Ação, São Paulo, 5: 43-53, 1982.

autores que enfocam sua análise no reconhecimento da luta de classes, ou que, pelo menos afirma a intenção de fazê-lo.

É o caso do trabalho de Lessa sobre os "quinze anos de política econômica" (13). Também aí, categorias analíticas como "política de desenvolvimento" e "industrialização intencional" supõem um sujeito de decisões inclusive quando se indica sua ausência ou insuficiente clareza, isto é, quando Lessa examina a "industrialização não-intencional"'. Referir-se a tal situação falando de "desperdício de divisas", importações não-essenciais, "erros" de política econômica, supõe um agente cujos projetos e ações se qualifiquem (mais ou menos desenvolvidas, conscientes ou corretas) conforme determinados cânones. Esse personagem, no trabalho de Lessa, é o responsável e interessado num "desenvolvimento autosustentado e independente", processo reputado possível pelo autor, ao fim do plano de metas do governo Juscelino Kubitschek $(13$, p.50). Nesse quadro não será difícil indicar, por sob o processo econômico, a existência duma tecnologia, ainda que seja pela afirmação de seu caráter oscilante, embrionário, etc. (13, p. 77-78).

É a imagem da coletividade, outro todo indiferenciado e indeterminado em cujo nome o Estado exerceria a violência - que definirá os fins visados, servindo como critério para aferir a legitimidade ou não das políticas econômicas, e, entre elas, das "economias externas" providenciadas pela atuação do setor público. Além do sistema de preços, a "pressão de forças e elementos que ultrapassam o universo econômico strictu-sensu (tais como legislação social, atuação dos sindicatos, decisões acerca de salário mínino, política monetária, fiscal etc.)" funcionarão como mecanismo de ajuste, de adequação da of erta à demanda. Isto posto, ao sujeito articulador dessas forças (os instrumentos de estado ou de vontade política, decisivos para a alocação de recursos) é atribuída uma posição tal de independên- cia e poder que se torna o centro do palco teórico e prático da política.

3. ISEB: objetividade reformista contra paixões socialistas.

Para os isebianos, a contradição central da sociedade brasileira é aquela existente entre a nação e a antinação (23). Nacionalizar o capital significaria, nesse contexto, reconstruir o país conforme a dinâmica das sociedades desenvolvidas, tomadas como modelo. Forjar a nação implicaria conquistas sociais, tais como garantia do emprego, tecnologia adequada aos recursos locais, maior mercado interno, instituições políticas modernas, etc. Neste sentido, o subdesenvolvimento será visto - não muito diferentemente do pensamento conservador dum Rostow (19) como etapa a ser superada por todas as sociedades nacionais. A sociedade brasileira passaria assim do não-ser (a colônia exportadora) ao ser (a nação industrializada), isto é, à fundação da sociedade civil e da nação coerente com sua própria identidade e essência. $\mathrm{O}$ mercado surge aí como origem, fonte do cosmos sóciopolítico, na forma de sua modernidade, conjugando eficácia, riqueza e justiça. Os isebianos em geral visam ainda definir qual o sujeito histórico que comandará esse processo em que se "forja a nacionalidade"'. Nos países desenvolvidos, esse elemento ativo fora gestado na própria crise do modo de produção anterior. E nos demais? Para essa definição, deve-se levar em conta que, para os isebianos, em linhas gerais, não há no Brasil uma estrutura de classes situada a partir do modo de produção. $\mathrm{O}$ antagonismo de classes só alcançará sentido e predominância no momento em que for implantado o capitalismo avançado. Por isso, se dirá que "o conceito de classe, que envolve necessariamente a dependência orgânica entre o explorador e o explorado, não pode exprimir legitimamente as condiçס̃es especiais de luta e emancipação das periferias colo- 
MORAES, R.C.C. de - A força das coisas: "etapas do desenvolvimento histórico" — notas de pesquisa. Trans/Form/Ação, São Paulo, 5: 43-53, 1982.

niais"*. Qual seria aí o sujeito que encarna a tarefa de forjar a emancipação, nesta fase da vida nacional? Há passagens de Guerreiro Ramos, por exemplo, em que se lamenta o fato de a burguesia nativa não compreender esse papel, como nos "casos clássicos". Ela existiria objetivamente mas não subjetivamente: "as forças políticas e o poder econômico estão nas mãos de pessoas jurídicas e físicas que, em larga escala, não têm consciência sistemática do projeto pressuposto por sua condição" $(18$, p. 20$)$. Qual o caminho para suprir essa ausência? Por vezes, na especificação desse Eu fantástico, simulacro da individualidade burguesa, se terá a defesa duma espécie de bismarckismo e apologia do Estado (Hélio Jaguaribe). Por outras, como em Álvaro Vieira Pinto, as "massas" seriam como que uma espécie de pólo avançado da "fração autóctone da nossa economia" (17,p.390). De qualquer modo, mesmo nesta última versão, ao proletariado caberia renunciar a veleidades propriamente socialistas, ou seja, a práticas políticas que evidenciassem a contradição capital/trabalho, definida como incompatível como a "fase" atual e, por extensão, contraproducente** do ponto de vista tático.

Mas a proximidade maior está com o pensamento autoritário brasileiro, que, desde Varnhagen, A. Torres e Oliveira Viana, acentuava o papel demiúrgico do Estado, diante da nação, em algo que se aparenta a uma leitura "bismarckiana" de Hegel: a opaca sociedade civil conformada pelo Estado, lugar da história, do movimento e da vontade. Em particular, é de se destacar, em O. Viana, a caracterização da nação brasileira como um ser em idade infantil, necessitado dum tutor: o
Estado autoritário. A formação socioeconômica brasileira - alicerçada no Latifúndio, geratriz da dispersão social, da não-existência de laços de solidariedade de classe - dependia, para sua maturidade, dum poderoso agente de vontade, 0 Estado.

$4 .^{\circ}$ - Maturidade política contra aventuras socialistas.

No início da década de 1960 , um dissidente do marxismo apologético, Leoncio Basbaum, lança um livro que se constitui em verdadeiro manif esto a favor duma "frente única" (sic) nacional e progressista: Caminhos brasileiros do desenvolvimento (2). Nele, em primeiro lugar, o autor toma como um dado a inferioridade numérica do proletariado brasileiro (e dos países subdesenvolvidos em geral), o que descarta a "hipótese" de uma ditadura do proletariado (2,p.282). Em segundo lugar, o autor afirma que o desenvolvimento das forças capitalistas é essencial para produzir, fisicamente, o proletariado brasileiro e criar assim as condições objetivas e subjetivas para o socialismo (2, p.286). Desse ponto de vista, nesta etapa, os antagonismos de classe deveriam ser deixados "num segundo plano, em benefício dos interesses gerais"' $(2, p .249)$. E como a "consciência socializante" (sic) já teria atingido setores da classe média, pequena e média burguesia $(2, \mathrm{p} .292)$, ficaria evidente como possível e necessário um governo popular que agrupasse as diferentes classes, dispostas a levar adiante esse projeto político, num programa mínimo comum (2, p.249 e 283).

Um outro autor da vertente marxista, Otávio Ianni, num escrito de 1963, esforçou-se por convencer o leitor da ne-

* Trata-se de Candido MENDES, citado por Maria Sylvia C. Franco (4, p. 15).

* Em economia, tais concepções seguramente deviam muito à escola cepalina, à idéia das economias latino-americanas como "economias reflexas" ou, nas palavras de Celso Furtado, como "projeção" do capitalismo ocidental em expansão. $\mathrm{Na}$ sociologia acadêmica, devem muito às chamadas teorias da modernização, que concebiam as sociedades latinoamericanas como "desintegradas", em oposição às "integradas" sociedades européias.

Para as teorias da modernização, a persistência da marginalidade, fruto da coexistência de tempos históricos distintos na mesma sociedade, constituiria limitação e ameaça para a sociedade industrial, porque impede a otimização dos recursos existentes (obstáculo pelo lado da produção) e porque reduz as possibilidades de expansão do sistema $(8, p .17)$. 
cessidade histórica da etapa nacionaldesenvolvimentista. Ianni afirma que apenas após a constituição plena do sistema capitalista de produção no país, ou seja, após a socialização da produção, se poderá efetivar a luta aberta do proletariado contra a burguesia (10, p.33). Para Ianni, no Brasil "a estrutura de classes se acha em formação", o proletariado não está amadurecido para deflagrar seu movimento político $(10$, p.54). Em outros termos, a insuficiente maturação das condições objetivas locais é posta como um dado que torna impossível a consciência operária como negação do sistema burguês $(10$, p.56-57).

\section{III - OS PRESSUPOSTOS COMUNS.}

Mais acima, tínhamos adiantado o argumento de que constituía uma prática comum aos autores examinados a aceitação do postulado do "interesse nacional", isto é, duma razão adormecida neste ser - a Nação - e que se desvela no curso da História, encontrando, para cada fase de sua vida, o sujeito sóciopolítico que se identifica com as potencialidades do seu desenvolvimento.

Evidentemente, há uma distância importante entre o pensamento dum Baer e os autores progressistas que acima mencionamos. Para o primeiro, a atividade política operária e a independência do movimento sindical se constituem, em qualquer momento, como obstáculo à administração científica da sociedade, centralizada num estado supostamente exterior e acima dos interesses de classe. Essa política operária aparecerá, em suma, como a figura da desrazão. Para os progressistas acima, a independência política do proletariado aparece antes como algo anacrônico, ou melhor, como uma antecipação histórica indevida, uma vez que, no Brasil, a classe operária não teria existência objetiva suficiente para se constituir politicamente como negatividade. A possibilidade inscrita na ordem das coisas seria a etapa do desenvolvimento nacional auto-sustentado, gerido pelo estado desenvolvimentista (Lessa), por um governo popular acima dos interesses de classe (Basbaum, setores do ISEB) etc.

Ora, de certo modo, a economia política da CEPAL formulou, de maneira academicamente mais rigorosa, esse tipo de postura. Trazendo para o debate contribuições até hoje valiosas, a CEPAL via a passagem das nações latino-americanas ao plano da realidade (já que elas seriam uma quase ficção) no quadro de desenvolvimento desigual da economia mundial. Passando da situação de economias reflexas (desenvolvimento econômico "para fora") - isto é, com o centro de seu destino localizado na demanda externa - para a de economia desenvolvida para dentro, as sociedades latino-americanas encontrariam vários obstáculos: contrastes entre tecnologia produtiva avançada (geradas no "centro") e capacidade de poupança débil; entre tecnologia importada com alta capacidade de produção e a relativa fragilidade da demanda; entre a geração do desemprego tecnológico e a não geração de uma indústria de bens de capital que absorvesse o excedente de força de trabalho (tendência ao desemprego estrutural) etc. O papel decisivo da política econômica, da ação estatal, para essa transição, é evidente: é pela audaciosa manipulação do perfil da demanda e pela ação sobre a variável investimento que se terá a alavanca para mover o mundo.

Já em 1963, Maria Conceição TAVARES apontava, timidamente, para 0 fato de que as análises da industrialização na América Latina, calcando-se em julgamentos de valor sobre os "erros da política econômica", "falta de racionalidade", "medidas não adequadas", supunham a independência do Estado diante das classes, o que era um tendão frágil. A autora, contudo, não deixa de, às vezes, supor esse interessante nacional, cujas luzes emanariam ora dos empresários inovadores (à la Schumpeter), ora do Estado (nos formuladores de política econômica), refe- 
MORAES, R.C.C. de - A força das coisas: "etapas do desenvolvimento histórico" — notas de pesquisa. $\quad$ Trans/Form/Ação, São Paulo, 5: 43-53, 1982.

rências que, de certo modo, constituíam herança da figura cepalina do "círculo vicioso da pobreza"*

Recentemente, num balanço dessas teses, Weffort insiste na importância que o marxismo apologético - por ele chamado de "teoria marxista clássica" — dá às “pesadas estruturas", na análise histórica. A seu ver, é isso que permite enfatizar, "no plano da teoria, a dependência da classe operária em relação ao desenvolvimento do sistema na mesma medida em que o argumento servia para justificar no período da 'revolução democráticoburguesa' uma política de subordinação da classe operária em relação à burguesia nacional, ou seja, a classe portadora das virtualidades do desenvolvimento do sistema''(24).

Volto ao ponto (I) deste texto: se se admite uma razão adormecida na nacionalidade informe, não constituída, a política correta seria destacada a partir das potencialidades de seu desenvolvimento. Se é assim, quem é, contudo, o mediador nesse processo? O exército? A tecnoburocracia? Os empresários “schumpeterianos"? O Estado, simplesmente? Quem, com o olhar iluminado pela razão, teria diante de si o mundo em absoluta transparência? Furtado cria, assim, a figura do intelectual, o mais lúcido $\mathrm{e}$, por isto mesmo, quase que um anestesista da revolução social, enquanto "único elemento dentro de uma sociedade que não só pode mas deve sobrepor-se aos condicionamentos sociais mais imediatos do comportamento individual" $(7, p .9)$. Rolando Corbisier faz da "intelligentsia nacional" um "órgão da consciência nacional", um instrumento da "tomada de consciência de um país por ele próprio" $(5$, p. 41 e 44).

Mas eis aí um movimento astucioso. Constituindo o objetivismo - o planejador-funcionário supostamente se submete ao "interesse nacional" (ISEB), à ordenação ótima da "economia" (BAER), às possibilidades objetivas do momento histórico (Basbaum etc.) - se legitima o subjetivismo. O planejadorfuncionário - na situação ou na oposição - apela para a invisibilidade do absoluto, a soberania nacional (ele é funcionário do universal...) para justificar o seu próprio e visível poder.

A análise daquilo que efetivamente é ou efetivamente pode ser avaliza as atitudes e programas políticos "corretos". Assim, Corbisier dirá que os "interesses do desenvolvimento do país coincidem com as reivindicações da burguesia industrial, com os setores esclarecidos da classe média e do proletariado industrial" (5, p.45). Esta coincidência objetiva legitimaria a formulação dum programa comum, autorizando a intelligentsia a "forjar a ideologia da libertação nacional" (5, p.45).

Nesse passo, não seria de espantar que - na vertente marxista apologética - se pudesse fazer da sucessão unilinear dos famosos "cinco modos de produção" a chave teórica que explicasse a revolução social no Brasil. O esquema dos cinco estágios cumpriria, na história social, papel de previsão análogo às teorias vigentes nas ciências naturais. Assim, N. Werneck Sodré, por exemplo, procuraria demonstrar a existência das etapas escravista e feudal da história brasileira (21, cap.I). Supondo o todo-sistema (os 5 estágios e suas leis), trata-se de apreender, pacientemente, as partes que necessariamente existem. A partir desse quadro, a formação social brasileira é caracterizada como dual (resquícios feudais versus capitalismo), com o que se definiria a etapa democrático-burguesa da revolução (21,

* Cf. "Auge e declínio do processo de substituição de importaçðes no Brasil", in Da substituição de importaçðes ao capitalismo financeiro (22)(ver, desse texto, as "conclusठ̃es", "perspectivas" e ainda a p. 46). Mais tarde, a autora retomaria a crítica da abordagem estagnacionista, avançando a tese de que, em alguns países da área, se teria crescimento econômico através da exclusão (2, p. 157, 158 e 166). 
MORAES, R.C.C. de - A força das coisas: "etapas do desenvolvimento histórico" - notas de pesquisa. Trans/Form/Ação, São Paulo, 5: 43-53, 1982.

p.384). O imperialismo tentaria explorar aquilo que, anedoticamente, veio a se chamar, depois, de "esquizof renia de classe" da burguesia nacional, dividida, segundo Sodré, entre os "seus interesses de classe" e os "interesses que são realmente os seus" $(\mathrm{sic})(21, \mathrm{p} .387)$. Essa análise do "real-objetivo" legitimaria um programa político que acentua o papel histórico da burguesia nacional na revolução brasileira e, ao mesmo tempo, "demonstra" que "as posições extremadas e sectárias que induzem o proletariado a ver na burguesia o inimigo principal"' $(21$, p.395) fazem, objetivamente, o jogo do imperialismo e da reação.

MORAES, R.C.C. de - The power of things: "stages in the historical development" - research notes. Trans/Form/Ação, São Paulo, 5: 43-53, 1982.

ABSTRACT: This text slightly modified, became the first chapter of our M.A. thesis - The Tropical Phoenix: a critical note about dualism and the theory of dependency, presented to the "Faculdade de Filosofia, Letras e Ciências Humanas" of the University of São Paulo. The main themes of this thesis are: I - "Philosophy of History", Marxism and "objectivity"; II - Brazilian social thinking: the theories of/about development and the apologetic Marxism: 1. ${ }^{\circ}$ Werner Baer: conservative "objectivity" against the reformist "passions"; 2. ' Carlos Lessa: Industrialization as "decision"'; 3. 'ISEB: reformist objectivity against socialist passions; $4 .^{\circ}$ Political maturity against socialist adventures; III Common presuppositions.

KEY-WORDS: Philosophy of history; marxism; objectivism; developmentalism; reformism; Brazilian sociology; nationalism; progressivism.

\section{REFERENCIAS BIBLIOGRÁFICAS}

1. BAER, W. - A industrialização e o desenvolvimento econômico do Brasil. Rio de Janeiro, Fundação Getúlio Vargas, 1975.

2. BASBAUM, L. - Caminhos brasileiros do desenvolvimento. S. Paulo, Fulgor, 1960.

3. BENICHOU, P. - Les temps des prophetes. Paris, Gallimard, 1977.

4. CARVALHO FRANCO, M.S. - O tempo das ilusðes. CEDEC, s/d. p. 15 (mimeo.).

5. CORBISIER, R. - Formação e problema da cultura brasileira. Rio de Janeiro, ISEB, 1958.

6. ENGELS, F. - Do socialismo utópico ao científico. São Paulo, Edições Sociais, 1977.

7. FURTADO, C. - Dialética do desenvolvimento. Rio de Janeiro, Fundo de Cultura, 1964.

8. GERMANI, G. - Política y sociedad en una época de transición. Buenos Aires, Paidos, 1962.

9. HEGEL, W. - Filosofia do direito. Trad. R. Derathé. Paris, Vrin, 1975.

10. IANNI, O. - Processo político e desenvolvimento econômico. In: IANNI, O. et alii. -
Politica e revolução social no Brasil. Rio de Janeiro, Civilização Brasileira, 1963.

11. LENIN, W. - Materialismo e empiriocriticismo. Paris, Editions Sociales, 1948.

12. LE ROY, M. - Histoire des idées sociales en France. Paris, Gallimard, 1954. t. III.

13. LESSA, C. - Quinze anos de política econômica. Campinas, Intituto de Filosofia e Ciências Humanas, Unive Jade de Campinas, 1975.

14. MARX, K. - El Capital. inuxico, D.F., Fondo de Cultura Economica, 1974. t. 1.

15. MARX, K. - Revolução e contra-revolução na Alemanha. Amadora, M. Xavier ed., 1976.

16. MERLEAU-PONTY, M. - Les aventures de la dialectique. Paris, Gallimard, 1955.

17. PINTO, A.V. - Consciência e realidade nacional. Rio de Janeiro, ISEB, 1960. vol II.

18. RAMOS, A.G. - As condiçðes sociais do poder nacional. Rio de Janeiro, ISEB, 1957. 
MORAES, R.C.C. de - A força das coisas: "etapas do desenvolvimento histórico" — notas de pesquisa. Trans/Form/Ação, São Paulo, 5: 43-53, 1982.

19. ROSTOW, W. - Etapas do desenvolvimento econômico. Rio de Janeiro, Zahar, 1967.

20. SAWER, M. - Marxism and the question of the asiatic mode of production. The Hague, Martins Nijhoff, 1977.

21. SODRÉ, N.W. - História da burguesia brasileira. Rio de Janeiro, Civilização Brasileira, 1964.
22. TAVARES, M.C. - Da substituição de importaçðes ao capitalismo financeiro. Rio de Janeiro, Zahar, 1973.

23. TOLEDO, C.N. - ISEB: fábrica de ideologias. São Paulo, Ática, 1977.

24. WEFFORT, F.C.-Sindicatos e política. São Paulo, Faculdade de Filosofia, Letras e Ciências Humanas, USP, 1972. (TeseDoutoramento). 